\title{
RAND
}

\section{The Effects of Large Capital Gains on Work and \\ Consumption: Evidence from Four Waves of the HRS}

Michael Hurd and Monika Reti

DRU-3011

October 2001

\section{Labor and Population Program}

\section{Working Paper Series 03-14}

The RAND unrestricted draft series is intended to transmit preliminary results of RAND research. Unrestricted drafts have not been formally reviewed or edited. The views and conclusions expressed are tentative. A draft should not be cited or quoted without permission of the author, unless the preface grants such permission. 



\title{
The Effects of Large Capital Gains on Work and Consumption: Evidence from four waves of the HRS
}

\author{
Michael Hurd
}

Monika Reti

\section{RAND}

October, 2001

Final Report

Prepared for the US Department of Labor under contract J-9-P-7-0045 



\section{Introduction}

Although it is natural to suppose that years of retirement are a normal good so that increases in wealth would lead to earlier retirement, it has been difficult for research to estimate plausible wealth effects on retirement. ${ }^{1}$ Part of the reason for the difficulty is that some of the cross-section variation in wealth is the result of taste variation: for example, people who are especially risk averse will tend to accumulate more wealth and to retire later than those who are less risk averse. Also it is difficult to control for the quality of the job: higher paying jobs tend to have amenities that make work more pleasant thus delaying retirement, and at the same time higher incomes are associated with greater rates of wealth accumulation. Such positive crosssection correlations between wealth and retirement age are apparently large enough to offset negative correlations induced by a wealth effect on retirement.

In panel data observed wealth change may not be related to a wealth effect on retirement. Economic models of wealth accumulation and retirement imply that individuals accumulate wealth so that they can retire at an optimal age. As long as there are no unforeseen changes in the environment or in other determinants of retirement, the optimal retirement age will not change over time. The constancy of the optimal anticipated retirement age holds whether individuals save at a high rate (large wealth accumulation) or at a low rate. The result is that we should observed no relationship between wealth change and changes in anticipated retirement simply because the anticipated retirement age would not change. Only when there are unanticipated changes in the determinants of retirement would the optimal anticipated retirement age change.

The stock market boom of the mid to late 1990s provides an opportunity to study what was likely an unexpected wealth change for at least part of the population. The boom produced wealth increases for some that were substantially similar to the thought experiment of giving large windfall wealth increases to the population that was approaching retirement, making it possible to avoid many of the difficulties associated with non-experimental data. The purpose of this paper is to study the associated change in actual retirement and in expected retirement of that population.

In 1992 the age-eligible respondents in the Health and Retirement Study (HRS) were approximately 51-61 (Juster and Suzman, 1995). Their financial resources included private savings, part of which was invested in the stock market, part in the bond market, and part in checking and savings accounts and other miscellaneous assets. They also had claims to pensions, some of which were DB plans and some DC plans.

\footnotetext{
${ }^{1}$ Two examples are Gustman and Steinmeier (1986) and Samwick (1998). Both report small wealth effects on retirement.
} 
Between wave 1 in 1992 and wave 2 in 1994, the stock market increased in value by 14\% as measured by the New York Stock Exchange Composite Index (NYSEI). However, beginning in 1994 stock prices increased at much greater rates than they had historically: between waves 2 and 4 in 1998 the NYSEI increased by 90\%. Thus between 1994 and 1998 many households had large gains in wealth. By historical projection, much of these gains would have been unanticipated and could reasonably be taken to be exogenous to previous decisions about saving and anticipated retirement.

Under the assumption that the gains in the stock market were unanticipated, the increase in wealth has aspects of a natural experiment in which some households had large gains in wealth in the years shortly before retirement and others did not. As in any experiment, there are some households that are controls and some that are experimentals. A number of households would have had similar economic positions in 1994 except that their portfolio mix differed: some held stocks and some did not. Some households had firm-directed DC plans that invested in stocks and some had plans that invested in bonds. These households would have had very different changes in the value of their private assets and in their DC plans, and the differential change would not have been expected and would have been only partially under their control. It is as if the different households had been assigned to different treatments in an experiment. Thus, variation in tastes that makes the interpretation of nonexperimental data so difficult is likely to be much less important.

A second type of control for tastes comes from comparing household behavior between 1992 and 1994 (when the stock market delivered normal returns) with household behavior after 1994. A third type of control comes from workers who had DB plans. Such workers would have had an orderly and well-anticipated change in pension value, so their behavior can be compared with workers that had large gains from DC plans that were invested in stocks.

In summary, there were large changes in wealth for some of the respondents, and some of the wealth change can be assumed to be unanticipated. Their behavior in the waves following the large changes can be compared with the behavior of respondents who had no such wealth changes, and the difference can be attributed to a windfall wealth effect.

Our main research question is: how did the large increase in wealth affect behavior? Broadly speaking, how was the gain from stock holdings spent? An obvious response for workers in the age range of the HRS is to buy more leisure by retiring earlier than anticipated. We will study actual retirement, and anticipated retirement as measured by the subjective probability of working past 62 , which is asked in every wave of HRS. We ask whether those with wealth gains retired earlier than those who did not have them, and whether anticipated retirement as measured by the subjective probability of working past 62 changed in the panel in response to the wealth changes. The difference between actual and anticipated retirement should be particularly informative as it will show whether those workers that had large gains in wealth actually retired earlier than their intentions as stated before any windfall gain in wealth. This will be a direct measure of the elasticity of retirement with respect to wealth that takes into 
account any individual propensity to retire.

The gain in wealth may be spent on consumption. We have several direct measures of consumption of varying quality in the HRS. There is a measure of food consumption that has been used with some success in studies of dynamic consumption behavior based on the PSID. There is the value of automobiles, so that, for example, we can find if the gains are spent on automobile purchases. There is housing which is carefully tracked in the HRS. In waves three and four there was a single total consumption question that aimed to find total expenditures by a household in a month.

\section{Wealth in the HRS population}

Table 1 shows cross-section income, wealth and some components of wealth, all measured at the household level. Income reached a maximum in wave 2 when the average age of the HRS cohort was about 58 and then began to decline as the cohort started to retire. Wealth was constant between waves 1 and 2 and increased moderately between waves 2 and 3 . There was a large increase in wealth and financial wealth especially between waves 3 and 4 . The increase is partly the result of the boom in the stock market. Although there was an increase in the fraction of the cohort holding stocks, from about $28 \%$ in wave 1 to $32 \%$ in wave 4 , the primary cause of the increase in stock wealth was gains in the value of stocks per household, not in the number of owners. Housing wealth was stable, increasing at a rate just slightly lower than the rate of increase of consumer prices (about $2 \%$ per year over each two-year period).

The change from wave to wave in cross-section income and wealth is not necessarily the average change experienced by individuals in the cohort because of differential mortality and differential sample attrition by socio-economic stratum. The less well-to-do die sooner than the better off and they attrite from the survey at a greater rate. These compositional changes will cause income and wealth to increase in cross-section as a cohort ages.

Table 2 controls for changes in composition by following the same individuals over each two-year panel comparison. For example, we observe data on 8,807 age-eligible persons over the two-year period between waves 1 and 2 . The income of the households of those respondents increased from about $\$ 46.7$ thousand to $\$ 50.6$ thousand, an increase of about $8 \%$. This compares with a cross-section two-year change from $\$ 46.0$ to $\$ 50.6$ (Table 1). Overall the change in the panel is about the same as the change in the cross-section which shows that differential mortality and differential sample attrition are not very important determinants of the characteristics of the HRS sample. ${ }^{2}$ As far as the wealth components are concerned, they also changed in the panel in about the same way as in the cross-section. A notable feature is the small decline in real net

${ }^{2}$ Although differential morality is rather strong, the total number of deaths is too small to have much influence on the sample characteristics. 
housing wealth even between waves 3 and 4 when total wealth increased substantially.

The second panel of Table 2 shows income and wealth of those who were owners of stocks in both of two consecutive waves. A comparison of income in wave 2 among the 1,995 who survived in the panel from wave 1 to wave $2(\$ 91.1)$ with the income in wave 2 of the 2,059 who survived from wave 2 to wave $3(\$ 91.0)$ shows that the panel aspects of the income data are not very important at the aggregate level. Similar comparisons across the other waves leads to the same conclusion.

The levels of total wealth and financial wealth of stock holders were much greater than average wealth. For example, in wave 1 stock owners had total wealth of about $\$ 489.8$ thousand whereas average wealth was just $\$ 231.1$ thousand. Furthermore the growth of wealth between the waves was much greater, especially between waves 3 and 4 . Possibly more relevant than the rate is the absolute level of the wealth of stock holders: wealth increased by about $\$ 180$ thousand between waves 3 and 4 . Only a relatively small fraction of the increase could have come from saving out of income because the total income over the two years was only about $\$ 160$ thousand. This relationship between wealth increase and income is in sharp contrast to the wealth change of the entire sample: for everyone, wealth increased by $\$ 56$ thousand yet total income was about $\$ 50$ thousand per year or $\$ 100$ thousand over the two years between waves. Thus for stock holders, the achieved saving rate including capital gains was about $110 \%$ whereas for the entire sample it was about $56 \%$.

Among stock owners, wealth in housing was considerably higher than average, and although the growth rate was somewhat higher between waves 1 and 2, overall it was not appreciably different from the average of the entire cohort. The implication is that the greater wealth gains of stock holders were not used to increase housing wealth: housing wealth was greater than average before the large gains in the stock market and only increased at about the rate of inflation between waves 3 and 4 .

Among stock holders in both waves, stock wealth increased between waves 3 and 4 by about $\$ 46$ thousand or $36 \%$. Over this same approximate period the New York Stock Exchange Composite Index increased by $57 \% .^{3}$ In that the total wealth gain was $\$ 180$ thousand, there appears to have been some portfolio adjustment, and other parts of the portfolios also had gains.

The next panel shows the financial situation of those who did not own stock in either of two successive waves. For example, 5,434 persons were in households that did not own stock either in wave 1 or wave 2. It is apparent that this group had much lower levels of income and of all types of assets including housing, and that the rates of growth of assets were zero or negative. Furthermore, this is the largest group of those considered here, about $60 \%$ of the sample.

The next panel shows income and wealth of those who did not own stock in a baseline

June 1, 1996-June 1, 1998 
wave but did own stock in the succeeding wave. The average income in this group was higher than of the entire sample, and considerably higher than the income of those who were not stock owners, but it was lower than the income of stock owners in both waves. This group had large wealth increases, especially between waves 3 and 4: about $\$ 245$ thousand, even more than among stock owners in both waves. Even among this group which had very large wealth gains, little if any was put into housing. For example, even though total wealth increased by about $79 \%$ between waves 3 and 4 average housing wealth increased by about $6 \%$, which is about the rate of increase of the CPI.

The final panel of Table 2 shows the financial information of those who owned stock in a baseline wave but not in the succeeding wave. Thus 561 persons were in households that exited from the stock market between waves 1 and 2. The overall pattern is one of fairly high wealth levels at the baseline wave but substantially lower wealth at the next wave. That is, ownership of stock predicts high wealth in cross-section, but eliminating stock from the portfolio predicts a fall in wealth. Furthermore, the decline in wealth was greater than the decline in the value of stock holdings. For example, between waves 1 and 2, stock wealth declined by about $\$ 35$ thousand but total wealth declined by about $\$ 105$ thousand. Housing wealth declined particularly between waves 1 and 2 . Overall these figures suggest financial distress, leading the households to sell-off their stock holdings, and even reduce their housing wealth.

In summary, Table 2 shows very active wealth dynamics with some groups gaining considerable wealth and some groups losing considerable wealth. From the point of view of wealth inequality, the groups with the highest initial wealth had the greatest wealth gains both in absolute terms and relative terms. These results suggest increasing wealth inequality over time in the HRS cohort.

Because of the exceptionally large wealth changes between waves 3 and 4 , we show in Table 3 the detailed components of wealth in the panel over those waves. Among all households business wealth, the value of IRAs and stock wealth increased notably. The large increase in IRAs was probably at least partly due to the stock market boom, but the HRS does not have information about the composition of IRAs that would allow an investigation of this speculation. The other components of wealth were little changed.

Among those who owned stocks in both waves business wealth, the value of IRAs, stock wealth and money in checking and savings accounts increased. In that checking and savings accounts have low and fairly stable rates of return, the increase in those holdings suggest rebalancing of portfolios in response to the stock market gains.

Among those who were not stock owners, average holdings of each type of wealth was small with the exception of housing. Furthermore, except for a $14 \%$ increase in IRAs, none of the wealth components increased substantially. Our overall impression is that this group, which constitutes about $60 \%$ of our sample, has not prepared very well for retirement via their own household saving. Of course, they are likely to be qualified for Social Security benefits and some may anticipate pension income. However, because of the positive correlation between 
household wealth and pension eligibility, it is likely that many of the households in this group do not have rights to a pension.

Among new entrants to the stock market, there were large increases in IRAs, real estate and stocks, and a decline in business assets of about $20 \%$. The contrast with stock owners in both waves, who had a very large increase in business assets, suggests that the new entrants were selling businesses and investing the receipts in IRAs, stocks and real estate.

Those who left the stock market between waves had large declines in business assets, real estate and stocks. The notable exception to the overall fall in wealth was an increase in IRAs. Apparently IRAs were shielded from the economic distress that is evident from the large wealth decline.

\section{Labor Force Participation in the HRS}

Work status is derived from a self-report of work status: whether working for pay, hours worked and a self-classification as to retired, partially retired or not retired. From this, people are coded as working full-time, part-time, unemployed, partly retired, retired or not in the labor force. A combination of the first four categories corresponds to the CPS definition of labor force participation.

Across the four waves of the HRS we observe a decline in the percentage of people working full-time and part-time (Table 4), and the percentage of those retired increased across waves for both full and partial retirement. Labor force participation declined with age (Figure 1). When compared with the labor force participation rates from the CPS, the HRS indicates slightly higher participation rates, although the trend line is mirrored. Labor force participation at each age was relatively constant for all interview years of the HRS (not shown).

Table 5 shows transitions from full-time work. About $81 \%$ of full-time workers in wave 1 were working full-time in wave 2 . In each successive wave the transition rate to full-time work decreased and the rates of retirement increased. There was some part-time work but the dominant route to retirement among full-time workers was to complete withdrawal from the labor force.

\section{Anticipated Retirement}

A major strength of the HRS is that it asks about anticipated retirement. This is especially important for this research as we can study the change in anticipated retirement and compare actual retirement with anticipated. We will base anticipated retirement on the subjective probability of working past age 62 . It was asked of all workers in the following way: 
"...thinking about work generally and not just your present job, what do you think are the chances that you will be working full-time after you reach age 62?"

The respondents had already been told to evaluate their chances "On a scale of $\mathbf{0}$ to $\mathbf{1 0}$ where 0 equals absolutely no chance and 10 equals absolutely certain..." If the chances of working after age 62 were positive, the worker was asked about the chances of working after age 65 . Because of the high rates of retirement at or near 62 we will base our measure of anticipated retirement on the chances of working after age 62 which we call P62. Figure 2 illustrates the variation in $\mathrm{P} 62$ by age across waves with a trend line fitted for each wave. For each wave, older individuals have higher subjective probabilities of work at age 62 . Holding age constant we find a general trend toward lower probabilities of full time work at age 62 from wave 1 to wave 4 .

As far as the validity of $\mathrm{P} 62$ is concerned, it has been shown to vary in cross-section with variables that induce retirement or are related to retirement. For example, eligibility for a DB benefit before age 62 is associated with actual retirement prior to age 62 and it reduces P62 (Hurd and McGarry, 1993). The implication is that P62 will predict actual retirement, and, indeed, is has considerable predictive power for retirement in the HRS panel (Hurd, 1999). While these results indicate that P62 has some validity, in this paper we would like to establish the validity of $\mathrm{P} 62$ as a predictor of the quantity of full-time work at age 62 . To do that, we would like to answer two main questions: Does P62 predict continuation of workers in full-time work? Is it properly scaled; that is, does it predict the level of full-time work at or shortly after age 62 ?

The first question, whether it predicts continuation in full-time work, can be addressed by finding whether those with lower subjective probabilities tend to leave full-time work before age 62 at a higher rate than those with higher subjective probabilities. Even if the subjective probability of working past 62 is not properly scaled, it could still be an adequate predictor of continuation in full-time work until age 62 .

Table 6 shows the average P62 as reported in earlier waves as a function of work status in later waves. For example, 190 respondents who were age 62 in wave 4 and working full-time reported an average $\mathrm{P} 62$ of $63.5 \%$ in wave 1 when they were approximately age 56 . They can be compared with 278 respondents who were not working full-time in wave 4: they reported an average $\mathrm{P} 62$ of $35.0 \%$ in wave 1 . This and other similar comparisons show that P62 is a rather consistent predictor of working full-time after age 62, even when assessed up to six years earlier.

The second question, whether P62 is properly scaled, could in principle be answered by comparing the average of $\mathrm{P} 62$ in some population with the average rate of full-time work when that population reaches 62 . This would be a valid comparison because the expected participation rate of each individual at age 62 is just $P 62$, so the average population participation rate is approximately the average P62. There are, however, several obstacles to carrying out this

${ }^{4}$ Participation at 62 is a binomial random variable which takes the value of 1 with probability P62 and the value of 0 with probability 1-P62 
comparison. First, even if each individual correctly states his or her probability of working past 62, intervening events such as an unexpected change in health status will cause a revision in P62. By itself, such a revision will not cause a divergence between the average of the subjective probabilities and the average population rate of working full-time after age 62 . If a population were fully informed of the probabilities of events that could influence retirement, these contingencies would be included in the calculation of P62. Thus, under rational expectations in a stationary environment, the average P62 should accurately predict the average rate of full-time work after age 62 . However, if there were unanticipated events that affect the entire population, the average of the subjective probability of working past 62 would no longer predict the average rate of working full-time after 62 . Such events might be an unanticipated improvement in health in the population or an unanticipated increase in wealth such as that which resulted from the stock market gains during the 1990 s.

We can test for proper scaling in two ways. First, we observe part of the population in, say, wave 1 that will reach age 62 in some future wave. The average P62 among workers in wave 1 should approximate the fraction of those same workers who are working full-time at age 62. Similar calculations can be made for other waves. Unfortunately, the query about P62 is somewhat ambiguous, and could be interpreted as working full-time shortly after the 62nd birthday or by the end of the year in which the person was 62 years old. Our response to the ambiguity will be to find the fraction of 62 year-olds working full-time and the fraction of 63 year-olds working full-time.

Table 7 shows averages of $\mathrm{P} 62$ and actual rates of working full-time at ages 62 and 63. The averages of P62 were calculated over workers in waves 1, 2 or 3 who at the time of interview were less than age 62 ; the actual rates of full-time work were calculated over data from later waves on workers who had passed their 62 birthday. For example, we identified 368 people who were age 62 in wave 2 and who were working in wave 1 when they would have been approximately age 60 . In wave 1 , their average subjective probability of working past 62 was $55.6 \%$; yet just $51.6 \%$ were observed working full-time when they were age 62 in wave 2 . Similarly we identified 203 people who were age 63 in wave 2 and were working in wave 1 when they would have been approximately age 61 . Their average subjective probability of working past 62 was $59.4 \%$, but just $49.8 \%$ were actually working full-time in wave 2 . The divergence between $\mathrm{P} 62$ and the percent working full-time is much greater in the second column than in the first column because some left full-time work while age 62. A comparison in the other waves between the average subjective probability of working past 62 and the actual rate of full-time work shows similar discrepancies: the average of the subjective probability is about five percentage points higher than the actual rate of full-time work at age 62 and about 13 percentage points higher than the rate at age 63 . We conclude that the most plausible target age is age 62, and that the main reason for the difference between P62 and the rate of full-time work among respondents who are 62 is due to retirement shortly after reaching age 62 . Even so the differences are small enough that they do not raise serious questions about the validity of the P62 measure. Of course, it is plausible that unanticipated macro events caused the entire population to leave the labor force earlier than anticipated. 
A second method of studying P62 for proper scaling is based on the population properties of P62 and how they evolve in the panel. The population properties of P62 are broadly of two types: successive cross-sections and panel. To see how they evolve, consider two extreme situations: in the first retirement is a completely controlled process with no uncertainty. At wave 1 all workers know their retirement ages, and if it is less than 62, P62 is zero; if it is greater than $62, \mathrm{P} 62$ is one. Between waves 1 and 2 some workers reach their retirement ages and retire. Under the assumption that no one re-enters the labor force the probability that the leavers would work past 62 is zero, but because they correctly knew they would be leaving the labor force between waves 1 and 2, they would have reported P62 to be zero in wave 1 . Thus were we to assign P62 to be zero in wave 2, it would be unchanging in the panel over this group.

Those who remained in the labor force from wave 1 to 2 continue to anticipate retiring at the same age as in wave 1, so P62 is either zero or one as it was in wave 1 . In panel the average P62 would be constant over this group. Therefore, the average P62 would be constant in panel when averaged over the population of both workers and leavers and the cross-section average would be the same in both waves. The cross-section average calculated only over workers would of necessity increase because in wave 2 that average excludes the leavers and they all reported $\mathrm{P} 62$ to be zero in wave 1.

Now consider the other extreme where retirement is a completely stochastic caused by a random health event or a random layoff. Under the assumption of rationality (workers know the probabilities of all events), P62 at time $t$ given that someone is in the labor force would be calculated as

That is, P62 is the weighted average of probabilities conditional on labor force status at $t+1$. If then it follows directly that

. This relationship holds at the individual level, so that when P62 is averaged over those who are in the labor force both at $t$ and at $t+1$, P62 will increase in the panel.

The population average of $\mathrm{P} 62$ in wave $t+1$ regardless of labor force status is

But the right-hand side of this equation is the same as the right-hand side of (1), so that the average P62 is constant in panel when calculated over the population regardless of labor force status in $\mathrm{t}+1$. This implies, of course, that the cross-section average over the whole population will be unchanging. 
The average P62 over workers in cross-section will increase from wave to wave provided the average $\mathrm{P} 62$ reported in wave 1 by the leavers is the same or smaller than the average reported by stayers. This condition will hold provided P62 has explanatory power for retirement.

We would expect the actual situation to lie somewhere between the two extremes: some workers are quite sure of their retirement age because of pension provisions or tastes. Others have only weakly defined retirement preferences and wait for random events to unfold. Nonetheless the predictions are the same: in a stable environment, average P62 should remain constant as a cohort ages. Even though new information may arrive at the individual level causing individuals to reassess their own subjective probability, the revisions should roughly sum to zero because individuals will have correctly forecast the average probabilities of the new information and the resulting revisions.

Were the probability of re-entry to the labor force zero, it would be rather easy to test for panel consistency of average P62. We would first find the average over workers in wave t. Then the average in wave $t+1$ would be

Under the assumption that

this reduces to

It is likely, however, that some who leave the labor force will return; hence the probability of working past 62 among those who left the labor force between a baseline wave and the succeeding wave is not zero. Because P62 is only asked of those who are working, we have no respondent reports by those who left the labor force on the probability of working past 62 nor on the probability of re-entry into the labor force. Therefore we calculate P62 among those who are working at wave $t$ but have left the labor force by wave $t+1$ in two steps. In the first we find $P\left(L F_{t+2} \mid\right.$ not $\left.L F_{t+1}, L F_{t}\right)$. We estimate this to be the population frequency of reentry into the labor force between waves $t+1$ and $t+2$ of those who were in the labor force at wave $t$ but not at wave $t+1$. In the second step we calculate the probability of working past 62 to be the probability of re-entry multiplied by $\mathrm{P} 62$ calculated over those who are in the labor force. Because of sample size, which causes stochastic variation in the probabilities of re-entry, we use smoothed probabilities by age as shown in Figure 3.

Among those workers who were approximately 53 in wave $t$ and who left the labor force by wave $t+1$, the probability of reentry by wave $t+2$ when they would have been about 57 was 
about 0.35 . This is a substantially higher probability of entry into the labor force than among all 55 year-olds because the latter group includes many who have never been in the labor force and so have a probability of entry close to zero. ${ }^{5}$ The probability of re-entry falls with age so that by age 61 (at wave $t+2$ ) it is about 0.20 .

Having calculated P62 for those who leave the labor force between wave $t$ and $t+1$ we can find the panel change in P62 for all who were in the labor force at wave $t$ whether or not they remained in the labor force to wave $t+1$.

Table 8 shows the results of our calculations of P62 in the panel. Among the 1,223 who were age 53-54 in wave 2, were working in wave 1 , and reported a value of P62 in that wave, the average value of $\mathrm{P} 62$ was $45.4 \%$. This average is composed of 98 reports by those who left the labor force between wave 1 and 2 and of 1,125 by those who remained in the labor force. The average P62 of those who left was just 29.9\%. This shows directly that P62 has considerably predictive power for labor force participation even at ages considerably less than 62 . Taking possible re-entry into account, we calculate P62 for that group in wave 2 to be $16.4 \%$. The average in wave 1 of those who remained in the labor force was $46.8 \%$ and the average in wave 2 was $46.0 \%$. The overall average is $43.6 \%$; therefore, the average probability of the cohort declined by two percentage points between the waves.

Although we would expect that, under stationarity, the average P62 of those who remained in the labor force to increase between the waves, in fact it did not. It should be noted, however, that at these younger ages the magnitude of the upward revision required to maintain stationarity is not large. The change in P62 among those who left the labor force was $13.5 \%$ and the probability of leaving was 0.08 . Therefore, had $\mathrm{P} 62$ been revised upward by 1.2 percentage points, P62 would have remained constant in the population. As this example suggests, the upward revision required to keep the population average constant varies directly with the probability of leaving the labor force, and this probability increased with age. Thus we should see a pattern of greater upward revision with increasing age. This pattern generally holds in Table 8. For example, the average upward revision among 59-60 year-olds who remained in the labor force was 2.3 percentage points, and among $61-62$ year-olds it was 9.5 percentage points.

Similar calculations for those who were 55-56 in wave 2, 57-58 in wave 2 and so forth show a sharply declining P62 by age among those who leave the labor force between the waves. This is mainly a consequence of the sharp decline in probability of re-entry as shown in Figure

\footnotetext{
${ }^{5}$ In wave 2, P62 was also asked of those not in the labor force. We compared our calculations of P62 with the self-reports and found the self-reports to be about seven percentage points higher. We do not use them in our analyses; nonetheless, we interpret the relatively close agreement to lend validity to our method.
} 
3. With the exception of the oldest age group, P62 declined in each age band between the waves, and there is no apparent pattern in the difference between the average in wave 1 and the average in wave 2. The main cause of the discrepancy is that the average P62 did not increase among those who remained in the labor force even though survival in the labor force for two years should lead to an increase or at least not a decrease: if workers knew the exact age at which they would retire, their reports of P62 would not change in the panel so that P62 would be constant among those who remained in the work force. If there are stochastic events that have positive probability of occurring and that can cause a worker to leave the labor force, the fact that a worker remained in the labor force should cause an upward revision in P62. Just as in a life table, survival for two years in the labor force increases the probability of survival in the labor force to any fixed age such as 62 . However, those who remained in the labor force reduced $\mathrm{P} 62$ between the waves except for the top age group. This suggests that there was some macro event common to all, which caused all to revise downward their estimates of P62. The overall average as shown in the last line of the table indicates a population reduction in P62 of 2.9 percentage points.

We cannot make similar calculations for those aged 53-54 in wave 3 because almost all of the age-eligibles were past that age by then. For the other age groups, the patterns are somewhat different from the pattern between waves 1 and 2. In particular, there is no strong downward revision in P62 among those who remained in the labor force between the waves. For example, in the age band 57-58, $\mathrm{P} 62$ was revised downward by 3.8 percentage points between waves 1 and 2 but it was revised upward by 0.6 percentage points between waves 2 and 3 . As a result the overall average changed by just 0.4 percentage points between waves 2 and 3 . Between waves 3 and 4 the average did not change at all between the waves.

These discrepancies suggest a pattern that the population average P62 falls at younger ages but it is fairly stable or even increasing at older ages. But it is premature to interpret this pattern as an age effect because we have just one observation at the youngest age band and two at the next youngest. Therefore, the pattern could be the result of a time effect: possibly there were macro events between waves 1 and 2 that caused those of all ages to revise downward P62. Just what that shock could be is not apparent from Table 7. Despite the discrepancies, the evolution of P62 in the panel shows very good consistency between the forecasts in successive waves: The average of $\mathrm{P} 62$ in wave $t$ was 47.0 and the average in wave $t+1$ was 45.6 (not shown).

At a broad level, however, the changes do not show any support for the hypothesis that the large capital gains, especially between waves 3 and 4, were used to finance early retirement or led to a reduction in $P 62$. As shown in the last line of the table, the average change from wave 1 to 2 was 2.9 , from wave 2 to 3 was -0.4 , and from wave 3 to 4 was 0.0 . Thus relative to the other waves the change from wave 3 to wave 4 was a change toward later retirement, not earlier.

\section{Wealth change and retirement probabilities}


We can, of course, perform a much sharper test of our hypothesis by studying wealth change at a more disaggregated level. Accordingly, we disaggregate the sample according to whether a household held stocks. Table 9 has financial information about our analytical sample. The sample is those who were working and reported P62 in wave $t$, and either reported P62 in wave $t+1$ or left the labor force, allowing us to calculate $\mathrm{P} 62$ as we described earlier. ${ }^{6}{ }^{\text {The }}$ income levels of this group are considerably higher than for the entire HRS population as reported in Table 2, especially in the later waves. For example, average incomes in Table 9 in waves 3 and 4 were about $\$ 62.2$ thousand and $\$ 59.9$ thousand, whereas for the entire population they were $\$ 49.6$ thousand and 46.5 thousand. The main reason for the difference is that everyone in Table 9 was working at baseline.

Wealth increased very substantially between waves 3 and 4 . As would be expected from the run-up in the stock market, wealth in stocks increased with a corresponding increase in financial wealth. But the increase in financial wealth only accounted for about one-third of the total increase; the other important component was business wealth (not shown separately).

In Table 10 we show the changes in the probability of working past 62 that are associated with the large wealth changes. As discussed earlier, the relevant population in each baseline wave is the working population selected to include those who report P62 and also selected to include those for whom we have a value (either reported by the respondent or calculated) of P62 in the succeeding wave. We call the baseline wave $t$ and the succeeding wave $t+1$. In waves 1 and 2 we observed 5,349 workers who satisfied these criteria (and for whom we had observations on household wealth including their stock ownership status in both waves). Their average household wealth in wave $t$, which is wave 1 in this case, was $\$ 238.2$ thousand, and their wealth increased by $1.7 \%$ by wave $t+1$ (wave 2 ). In that all values are in nominal dollars, real wealth declined over this period. On average P62 decreased from 47.4 to 44.6 , a decline 2.8 percentage points or six percent. The average P62 in wave 2 is calculated over actual reports by those who remained in the labor force, and over our estimate of the probability of working past 62 among those who left the labor force between waves.

There were 1,306 respondents who were in households that owned stocks in both waves 1 and 2. These households had an average increase in wealth of $5.6 \%$. Among the 3,101 respondents who did not own stock in either wave, wealth declined by $4.9 \%$, so that in real terms wealth declined by about $10 \%$ between the waves. New entrants into stock holding had large wealth gains, and exiters from stock holding had substantial wealth declines.

The relationship between wealth and $\mathrm{P} 62$ in cross-section suggests that wealth gains would be partially used to finance earlier retirement: those who owned stock in both waves $t$ and

${ }^{6}$ The sample size varies across tables because of missing value and of sample selection. For example, Table 8 includes all age-eligibles, but Table 7 includes only those in the specified age bands, which excludes some age-eligibles. 
$t+1$ had the most wealth in wave $t$ and also the lowest average P62; those who owned stock in neither wave had both the lowest wealth and the highest P62. Thus, high wealth is associated with earlier expected retirement in cross-section.

In wave 2 the cross-section relationship between wealth and P62 continues to hold approximately: those with the most wealth (stockowners is both waves 2 and 3 ) had the lowest average P62, and those who owned no stock in either wave or were new entrants into stockholding had the highest average P62. However, in the panel there is no systematic relationship between wealth change and the change in P62: stockowners in both waves and new entrants into stock holding both had large gains in wealth; yet in one case P62 declined and in the other case it increased. Those who did not own stocks or those who left stockholding both had wealth declines (in real terms); yet P62 declined in one case and increased in the other.

Averaged over all respondents, wealth increased by $35.2 \%$ between waves 3 and 4 and P62 increased by $0.1 \%$. Comparing the overall change in wealth and P62 from waves 1 to 2 with the overall change in wealth and P62 from waves 3 to 4 we find little support for the idea that large changes in wealth led to earlier retirement: over the first two waves real wealth fell and P62 declined; between waves 3 and 4 real wealth increased substantially, yet P62 remained essentially unchanged.

This conclusion is reinforced when we compare the wealth change of stock owners with the wealth change of those who owned in neither wave. Among those who owned in both waves 3 and 4 wealth increased by $\$ 293.8$ thousand or $58.6 \%$, yet $P 62$ increased by 1.1 percentage points. Among those who owned in neither wave, wealth declined in real terms and P62 increased by just 0.2 percentage points. If we consider those who owned stock in neither wave to be a control group that on average had its expectations realized with respect to health, earnings and so forth, its lack of revision in P62 suggests stationarity. Under our hypothesis stock owners should then have revised downward the probabilities of working past 62: instead they revised them upward.

New entrants into stock ownership do exhibit some of the behavior we would anticipate were wealth gains to be unexpected and were unexpected wealth gains to reduce the anticipated retirement age. Between waves 1 and 2, and 3 and 4 wealth increased by large amounts and P62 declined by about 3.5 to 3.7 percentage points.

Those who exited from the stock market between the waves initially had high levels of wealth, a reflection of the fact that at baseline they were owners of stock. But between the waves their wealth decreased substantially. There is no obvious relationship between changes in wealth and changes in P62 for this group.

A possible explanation for the lack of a wealth effect on P62 is that we have not controlled for age. To do that we limit the presentation to a comparison between those who owned stocks in both waves and those who owned stock in neither wave. In that these two groups experienced the greatest difference in wealth change, we expect that they will have the 
greatest difference in the change in retirement expectations.

Table 11 shows these changes. As an example of the overall results, consider those who were 59-60 in wave 4 . Between waves 3 and 4, 253 stock owners had a remarkable wealth increase of about $\$ 400$ thousand or $73.1 \%$, while non-stock owners had a wealth decrease of $\$ 8.9$ thousand or $7.5 \%$. Stock owners reduced $\mathrm{P} 62$ by 2.0 percentage points and non-stock owners increased $\mathrm{P} 62$ by 2.6 percentage points. This comparison is consistent with the hypothesis that some of the large wealth gains will be used to finance earlier retirement. However, the same comparison over those 61-62 in wave 4 would lead to the opposite conclusion: the wealth of stock owners increased by $66.7 \%$, yet $\mathrm{P} 62$ increased by 5.6 percentage points. Non-stock owners had little change in wealth and a 0.6 percentage point increase in $\mathrm{P} 62$. As these examples show, there is little relationship between changes in wealth and changes in P62.

A way to summarize the results in Table 11 is from the regression of the percent change in P62 on the percent change in wealth over stock owners taking as the unit observation an agewave cell. Thus there are five observations from wave 1 to 2 , four observations from wave 2 to 3 ; and three observations from wave 3 to 4 . The estimated coefficient on the change in wealth is 0.07 and is not statistically significant. Furthermore, according to the theory, it is of the wrong sign: a one percent increase in stock wealth is associated with 0.07 increase in P62, whereas the theoretical prediction would be that $\mathrm{P} 62$ should decrease.

Although the results we have presented (which are based on individual data aggregated to groups as defined by age and stock ownership status) show no systematic pattern connecting wealth change with change in P62, it is possible that some individual-level covariates have been averaged in such a way as to obscure a real effect. To check for this possibility we estimated a number of regressions which took the form of the change in P62 on measures of wealth, stock ownership, pension status, marital status, health status and education. Of particular interest are variables that define eligibility for pension benefits. We have constructed categorical variables that indicate whether a worker has a DB plan on his or her job, whether the worker was eligible for benefits prior to the baseline wave, whether the worker became eligible between the baseline wave and the next wave, and whether the worker had not yet become eligible. In panel these variables have substantial explanatory power for actual retirement (Hurd, 1999). Here, however, we do not expect that they will have explanatory power because the left-hand variable is the change in P62. In a stable environment none of the right-hand variable should have explanatory power. For example, those who become eligible for DB benefits between waves 2 and 3 will have a high retirement hazard rate, but if workers knew at wave 2 that they would become eligible and as a consequence would leave the labor force, they would have reported a small value of P62 at wave 2. Observing that they did indeed leave the labor force we would have estimated P62 in wave 3 to be the compound probability of re-entry and working until 62 , which is also a small number. Thus, the change in P62 would be small and could approach zero. Similar reasoning will show this to be true of the other variables such as health status and 
education. ${ }^{7}$ Exceptions are wealth level and stock ownership, which are good predictors of large changes in wealth and which we believe to be substantially unexpected. Therefore, they should predict changes in P62.

Of course, changes in explanatory variables that represent new information should have explanatory power for the change in P62. An example would be a change in health status. 
Table 12 shows the results from such a regression for the wave 3 to wave 4 transition. ${ }^{8}$ No variable is statistically significant, and even the regression is not significant. Stock ownership itself is associated with an increase in P62. Increases in baseline wealth among stock owners are associated with a decrease in $\mathrm{P} 62$ in wave 4, but the elasticity is very small, about 0.01. Furthermore, the effect is about same as the effect of an increase in wealth among nonstock owners, whereas our prior was that it would be larger due to the unexpected nature of the stock market gains.

The largest of the pension effects is associated with eligibility prior to wave 3 : those who were eligible increased P62 between the waves. Having a limitation that restricts the type or amount of work is associated with a decease in P62. Although these results are of interest and possibly worthy of further investigation, none is significant and so they could simply be the result of stochastic outcomes.

Holders of DB pension plans were likely to be affected differently from holders of DC pension plans by the boom in the stock market: their pension entitlements do not depend on the performance of the stock market whereas at least some DC holdings are invested in the stock market. We classified workers according to whether they had a DB, a DC or no plan on their job in wave 1. Table 13 shows average wealth and average P62 according to that classification.

Those with a pension, either DB or DC, have more non-pension wealth than those without a pension. Those with a DC plan have somewhat more non-pension wealth than those with a DB plan and between waves 1 and 3 the non-pension wealth of DC holders grew at a greater rate: about $21 \%$ versus $15 \%$. But the large difference in growth rates was between waves 3 and 4 when non-pension wealth of DC holders increased by about $76 \%$ compared with just $12 \%$ for DB holders. By wave 4 DC holders had somewhat more than twice the non-pension wealth of DB holders. In that the wealth measure does not include pension wealth, the difference in the growth of total wealth is likely to be greater because DB wealth would not have been affected by the stock market boom whereas at least some of DC wealth would have been.

Holders of DC pensions had higher baseline values of P62 mostly likely due to the early retirement incentives of DB plans, which would depress $P 62$. But what is most notable is that between waves 3 and 4 P62 actually increased among holders of DC plan: even though nonpension wealth increased by approximately \$230 thousand, DC holders either retired later than they had anticipated or modified their plans to retire later. As with our classification by stock owning status, there is no systematic pattern between change in wealth and change in P62.

\section{Wealth Change and Consumption}

We found no evidence that the large changes in wealth between waves 3 and 4 were used

${ }^{8}$ Results from the transitions between other waves are similar. 
to finance earlier than expected retirement. The other major use of the wealth gain would be to increase consumption. The HRS has only limited direct measures of consumption. In waves 1,2 and 3, the survey queries about food expenditures, and especially expenditures on eating out which are thought to be particularly responsive to wealth. In waves 3 and 4 the survey had a one-question measure of total spending in the preceding month, that is, how much the household spent on everything in the past month. The respondents are instructed to think about all bills such as rent, mortgage loan payments, utility, insurance and other bills, as well as all expenses such as food, clothing, transportation, entertainment and any other expenses and come up with a rough amount. This summary measure has been shown to underestimate expenditures in the population aged 70 or over (Hurd, et al. 1998), but it varied appropriately as economic status varied, leading us to believe that it should increase if actual purchases do increase.

Table 14 shows assets, P62 and expenditures on eating out and food in waves 2 and 3 , and total expenditures in waves 3 and 4 . The sample sizes are substantially reduced from those reported in prior tables because of missing values on the expenditure items. In wave 2 stockowners spent somewhat more on food and substantially more on eating out than those who owned in neither wave, providing some validity to our measures. Spending on eating out in particularly seems to vary with assets: in wave 2 there is a monotonic relationship between net assets and eating out. We note, however, that the implied wealth elasticities are small.

As far as the changes in panel between waves 2 and 3 are concerned, we see that the results with this selected sample are generally consistent with our prior results. Stockholders in both waves and new stockholders had wealth gains whereas those who did not own stocks had constant or declining wealth. The panel change in spending on eating out does not follow the cross-section pattern. For example, those who did not own stock in either wave experienced a small decline in nominal wealth yet spending increased.

Between waves 3 and 4, the results on asset change and the change in P62 are qualitatively the same as in Table 10 with large wealth increases among stock owners and small or declining wealth change for non-stock owners. As before there is no consistent relationship between the change in wealth and the change in P62. Despite the increase in wealth of $69.1 \%$ among those who owned stocks in both waves, total monthly expenditures actually declined by $0.5 \%$ or $6 \%$ in real terms. New entrants into stock holding had an increase in wealth of $44.4 \%$, yet their spending decreased by $5.6 \%$ in nominal terms or more than $10 \%$ in real terms. Under the assumption that those who owned stock in neither wave had their anticipations realized with respect to rates of return on assets, the pure life-cycle rate of consumption change was approximate zero in real terms. Thus we do not see any effect of the large increases in wealth that are associated with the stock market boom on our measure of monthly consumption expenditures.

\section{Conclusions}

Between waves 3 and 4 of the HRS the stock market increased in value at substantially greater rates than in recent history, and, accordingly, we observe a large increase in the asset 
holdings of HRS households. We assumed that much of the increase in wealth was unanticipated because of the very much greater rates of return than had been experienced in prior years. Our major question was to find how households used this wealth gain.

We found no evidence that workers in those households which had large gains retired earlier than they had anticipated or that they revised their retirement expectations compared with workers in households that had no large gains. We can compare these results with those of Imbens, Rubin and Sacerdote (forthcoming). They estimated the effect of windfall gains in wealth from the behavior of lottery winners. Their basic finding was that large gains induced a reduction in labor force participation. Based on a comparison of the change in labor force participation of winners with the change in labor force participation of losers (Imbens, Rubin and Sacerdote, forthcoming, Table 2) we calculate that a windfall gain of about $\$ 300,000$, which is approximately the wealth gain between waves 3 and 4 of stockholders in both waves, would reduce labor force participation by about one percentage point. We interpret this to be a rather small effect, basically indistinguishable from our main finding.

Holtz-Eakin, Joulfaian and Rosen (1993) used IRS data on inheritances to estimate the effect of large wealth gains on labor force participation. Based on their estimates we calculate that a wealth gain of about $\$ 300,000$ would reduce participation by about seven percentage points. This is a substantially different magnitude from what we actually found.

There is one direct estimate in the literature of the effect of wealth on P62 (Hurd and McGarry, 1993). Based on estimation in that paper we calculate that a $\$ 300,000$ wealth gain would reduce $\mathrm{P} 62$ by about 2.6 percentage points. A possible explanation for the difference between that estimate and ours is that the adjustment to a windfall wealth gain takes time: indeed Imbens, Rubin and Sacerdote find that the adjustment time of lottery winners was several years.

We realize that in making these comparisons we have assumed that the entire gain in wealth by stockholders was unanticipated whereas in reality at least some of the gains would have been anticipated. We have no method of separating anticipated from unanticipated gains, but were we able to isolate unanticipated gains, the difference between our results and the results from Holtz-Eakin, Joulfaian and Rosen and from Hurd and McGarry would be reduced.

We found no evidence that the large gains in wealth were used to finance consumption: between waves 3 and 4 total monthly expenditures actually decreased among those with large capital gains. Furthermore, as reported in Table 3, holdings of vehicles and housing assets by those households were essentially unchanged between the waves, indicating that there was no sudden increase in spending on those items.

This finding is contrary to prior results on the effects of stock market wealth on consumption. Poterba (2000) offers a summary of the literature that for every dollar increase in stock market wealth, consumption will increase by about 5 cents. According to this estimate the gain in wealth by stockholders between waves 3 and 4 should have led to an increase in consumption of about $\$ 1,000$ per month. This is a large increase which should have been 
detectable even with the imperfect measure of consumption that was fielded in HRS waves 3 and 4. We conclude that the results in the literature are likely an overestimate of the effects of windfall gains in the stock market.

Guided by the life-cycle model, we began this research with the expectation that the large wealth gains would be at least partly spent on earlier retirement. Our thinking was that the gains were analogous to the thought experiment of giving a relatively large group of older workers a windfall wealth shock. What actually happened was probably more complicated. There was, indeed, a large wealth gain that we believe was largely unanticipated. But most likely the gain was accompanied by a change in the expectation of the normal rate of return on the stock market. Evidence for this conjecture is partly anecdotal. In addition, however, without such a change in expectations it would be difficult to explain the large increase in the rate of stock holding. For example, between waves 1 and 4 the rate of stock ownership in the HRS increased by about 4 percentage points or about $15 \%$. In the population aged 70 or over about $15 \%$ of households who did not own stock in 1993 had become owners by 1995 (Hurd, forthcoming). If indeed the anticipated rate of return from holding stocks increased substantially, the life-cycle model cannot make a prediction about a contemporaneous increase in consumption: the substitution toward saving induced by the large increase in the reward from saving could overcome the income effect resulting from the large gains to wealth.

We will have to wait for data from HRS 2000 and possibly from HRS 2002 to test this theory. During the survey year of 2000 some, but by no means all, of the wealth gains were lost in the stock market decline, and it is likely that anticipated rates of return in the stock market were revised downward. Such a change could lead to an increase in consumption out of the remaining windfall wealth gains. For the present, however, based on waves 1 through 4 of the HRS, the wealth gains resulting from the stock market boom were saved in their entirety. 


\section{References}

Gustman, Alan and Thomas Steinmeier, 1986, “A Structural Retirement Model," Econometrica, 54 (3): 555-584.

Holtz-Eakin, Douglas, David Joulfaian, and Harvey Rosen, 1993, “The Carnegie Conjecture: Some Empirical Evidence," Quarterly Journal of Economics, 108 (2): 413-435

Hurd, Michael D., 1999, "Labor Market Transitions in the HRS: Effects of the Subjective Probability of Retirement and of Pension Eligibility," in Wealth, Work and Health: Innovations in Measurement in the Social Sciences, James P. Smith and Robert Willis, editors, University of Michigan Press, pp 267-290.

Hurd, Michael D, forthcoming, "Portfolio Holdings of the Elderly," in Household Portfolios, Luigi Guiso, Michael Haliassos, and Tullio Jappelli, editors, Cambridge, MA: MIT Press

Hurd, Michael and Kathleen McGarry, 1993, "The Relationship Between Job Characteristics and Retirement," presented at the HRS Early Results Workshop, Ann Arbor, September, 1993, and NBER Working Paper 4558.

Hurd, Michael D., Dan McFadden, Harish Chand, Li Gan, Angela Merrill and Michael Roberts, 1998, "Consumption and Saving Balances of the Elderly: Experimental Evidence on Survey Response Bias,", in D. Wise, ed., Frontiers in the Economics of Aging, Chicago: University of Chicago Press, pp 353-387.

Imbens, Guido, Donald Rubin and Bruce Sacerdote, forthcoming, "Estimating the Effect of Unearned Income on Labor Earnings, Savings and Consumption: Evidence from a Survey of Lottery Players, American Economic Review, 2001 (September).

Juster, F. Thomas and Richard Suzman, 1995, "An Overview of the Health and Retirement Study, Journal of Human Resources, 30 (Supplement), S7-S56.

Poterba, James, 2000, "Stock Market Wealth and Consumption," Journal of Economic Perspectives, 14 (2): 99-118

Samwick, Andrew, 1998, "New Evidence on Pensions, Social Security and the Timing of Retirement," Journal of Public Economics, 70 (2): 207-236 
Table 1

Average income and wealth (thousands) of age-eligible respondents, cross-section

\begin{tabular}{|l|c|c|c|c|l|l|l|l|}
\hline Wave & N & $\begin{array}{l}\text { Total } \\
\text { household } \\
\text { income }\end{array}$ & Total wealth & Financial & Housing & Stock & $\begin{array}{l}\text { Number } \\
\text { stock } \\
\text { owners }\end{array}$ & $\begin{array}{l}\text { Percent } \\
\text { stock } \\
\text { owners }\end{array}$ \\
\hline 1 & 9825 & 46.0 & 228.9 & 48.3 & 63.5 & 18.6 & 2753 & 28.0 \\
\hline 2 & 8807 & 50.6 & 238.7 & 61.4 & 65.3 & 26.3 & 2812 & 31.9 \\
\hline 3 & 8335 & 49.0 & 263.0 & 70.2 & 66.7 & 36.6 & 2692 & 32.3 \\
\hline 4 & 7942 & 46.2 & 322.6 & 95.3 & 68.6 & 49.6 & 2533 & 31.9 \\
\hline
\end{tabular}

Note: Financial wealth is the sum of the holdings of stocks, checking and savings accounts, bonds, certificates of deposit, and other minus debt. See Table 3 for detailed listings.

Table 2

Average income and wealth (thousands) of age-eligible respondents, panel

\begin{tabular}{|c|c|c|c|c|c|c|c|c|}
\hline$\overline{\text { Wave }}$ & $\mathrm{N}$ & $\begin{array}{c}\text { Total } \\
\text { Household } \\
\text { Income }\end{array}$ & $\begin{array}{c}\text { Total } \\
\text { Wealth }\end{array}$ & Financial & Housing & Stock & $\begin{array}{l}\text { Number } \\
\text { stock } \\
\text { Owners }\end{array}$ & $\begin{array}{c}\text { Percent } \\
\text { Stock } \\
\text { Owners }\end{array}$ \\
\hline \multicolumn{9}{|l|}{$\overline{\text { All }}$} \\
\hline 1 & 8807 & 46.7 & 231.1 & 49.2 & 64.0 & 19.2 & 2556 & 29.0 \\
\hline 2 & 8807 & 50.6 & 238.7 & 61.4 & 65.3 & 26.3 & 2812 & 31.9 \\
\hline 2 & 8036 & 51.6 & 240.4 & 62.5 & 65.4 & 26.6 & 2644 & 32.9 \\
\hline 3 & 8036 & 49.2 & 264.0 & 70.5 & 66.8 & 36.6 & 2619 & 32.6 \\
\hline 3 & 7609 & 49.6 & 271.1 & 72.5 & 67.9 & 37.9 & 2526 & 33.2 \\
\hline 4 & 7609 & 46.5 & 327.1 & 97.0 & 69.4 & 50.4 & 2474 & 32.5 \\
\hline \multicolumn{9}{|c|}{ Stockowners in both waves } \\
\hline 1 & 1995 & 71.9 & 489.8 & 146.8 & 106.0 & 75.0 & 1995 & 100.0 \\
\hline 2 & 1995 & 91.1 & 532.6 & 180.9 & 116.1 & 94.7 & 1995 & 100.0 \\
\hline 2 & 2059 & 91.0 & 497.9 & 170.7 & 111.7 & 89.0 & 2059 & 100.0 \\
\hline 3 & 2059 & 80.7 & 566.6 & 204.8 & 109.3 & 128.2 & 2059 & 100.0 \\
\hline 3 & 1925 & 81.8 & 581.4 & 205.8 & 115.5 & 125.9 & 1925 & 100.0 \\
\hline 4 & 1925 & 76.6 & 761.0 & 289.6 & 119.9 & 171.5 & 1925 & 100.0 \\
\hline \multicolumn{9}{|c|}{ Stockowners in neither wave } \\
\hline 1 & 5434 & 33.8 & 117.5 & 12.4 & 44.1 & 0.0 & 0 & 0.0 \\
\hline 2 & 5434 & 33.0 & 112.7 & 15.0 & 44.2 & 0.0 & 0 & 0.0 \\
\hline 2 & 4832 & 33.2 & 113.6 & 14.9 & 41.9 & 0.0 & 0 & 0.0 \\
\hline
\end{tabular}




\begin{tabular}{|c|c|c|c|c|c|c|c|c|}
\hline 3 & 4832 & 32.7 & 120.7 & 14.4 & 45.0 & 0.0 & 0 & 0.0 \\
\hline 3 & 4534 & 32.0 & 118.2 & 13.4 & 44.5 & 0.0 & 0 & 0.0 \\
\hline 4 & 4534 & 30.6 & 119.1 & 14.1 & 44.0 & 0.0 & 0 & 0.0 \\
\hline \multicolumn{9}{|c|}{ Entrants into stockowning } \\
\hline 1 & 817 & 56.9 & 241.5 & 29.0 & 79.8 & 0.0 & 0 & 0.0 \\
\hline 2 & 817 & 60.3 & 323.0 & 89.0 & 81.8 & 51.8 & 817 & 100.0 \\
\hline 2 & 560 & 61.4 & 270.9 & 49.3 & 82.7 & 0.0 & 0 & 0.0 \\
\hline 3 & 560 & 65.2 & 368.4 & 99.6 & 91.5 & 53.4 & 560 & 100.0 \\
\hline 3 & 549 & 62.5 & 310.6 & 39.0 & 81.0 & 0.0 & 0 & 0.0 \\
\hline 4 & 549 & 64.0 & 555.7 & 158.4 & 86.1 & 97.7 & 549 & 100.0 \\
\hline \multicolumn{9}{|c|}{ Exiters from stockowning } \\
\hline 1 & 561 & 67.2 & 396.5 & 88.8 & 85.5 & 35.4 & 561 & 100.0 \\
\hline 2 & 561 & 62.1 & 291.3 & 45.7 & 64.5 & 0.0 & 0 & 0.0 \\
\hline 2 & 585 & 55.9 & 352.7 & 87.4 & 80.3 & 52.0 & 585 & 100.0 \\
\hline 3 & 585 & 58.9 & 282.1 & 33.0 & 73.9 & 0.0 & 0 & 0.0 \\
\hline 3 & 601 & 66.9 & 395.0 & 121.8 & 79.4 & 76.6 & 601 & 100.0 \\
\hline 4 & 601 & 54.1 & 298.1 & 49.4 & 83.5 & 0.0 & 0 & 0.0 \\
\hline
\end{tabular}


Table 3

Wealth and wealth components, waves 3 and 4 (thousands)

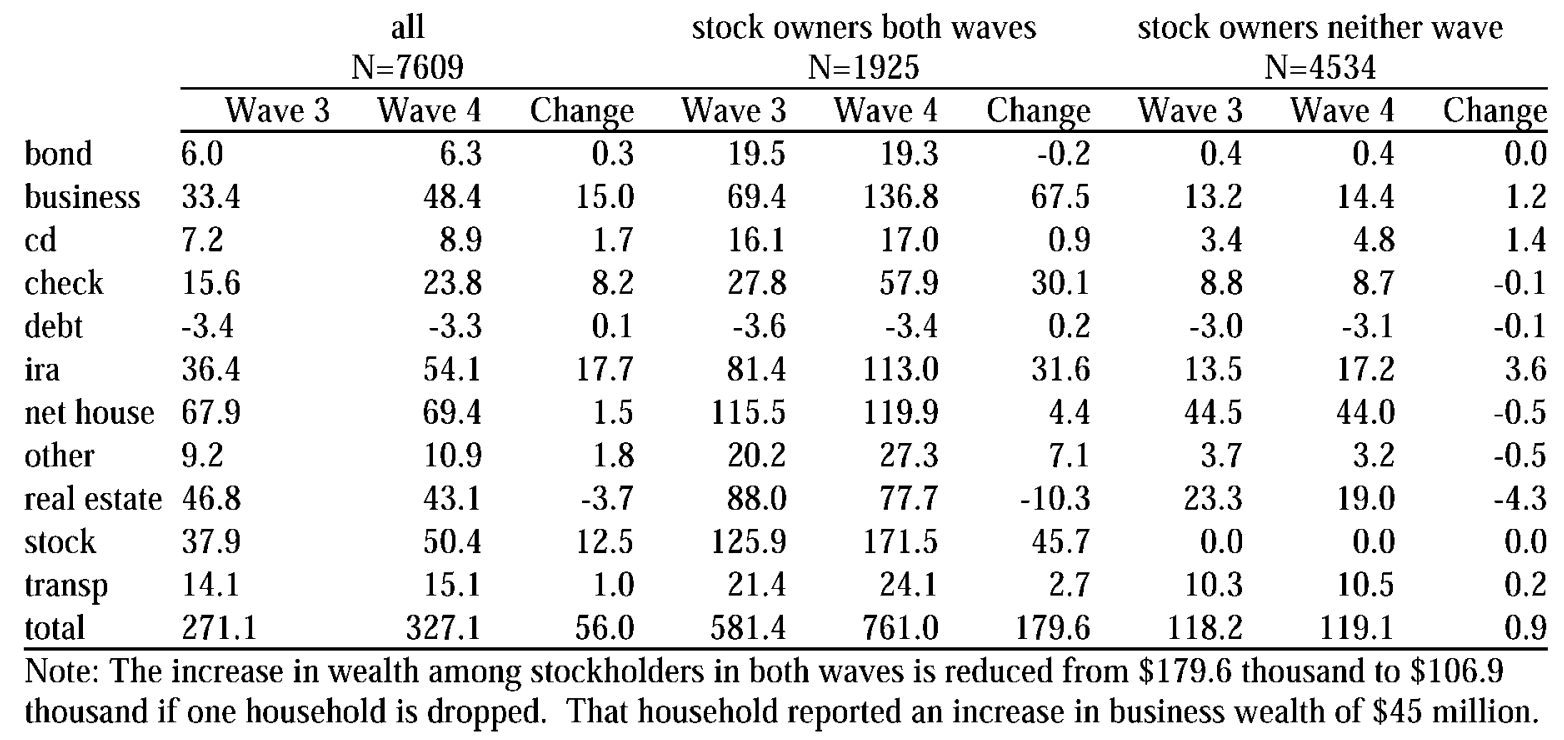

Wealth and wealth components, waves 3 and 4 (thousands)

\begin{tabular}{lrrrrrr} 
& \multicolumn{3}{c}{ stock owners wave 4 only } & \multicolumn{3}{c}{ stock owners wave 3 only } \\
& \multicolumn{3}{c}{$\mathrm{N}=549$} & & & \\
& Wave 3 & Wave 4 & Change & Wave 3 & Wave 4 & Change \\
\cline { 2 - 7 } bond & 1.7 & 6.8 & 5.2 & 8.5 & 8.1 & -0.4 \\
business & 62.7 & 50.5 & -12.2 & 44.4 & 20.1 & -24.3 \\
cd & 7.1 & 11.8 & 4.7 & 7.1 & 11.2 & 4.1 \\
check & 24.4 & 28.2 & 3.8 & 19.8 & 24.1 & 4.3 \\
debt & -4.5 & -4.1 & 0.4 & -4.5 & -4.2 & 0.3 \\
ira & 48.8 & 133.5 & 84.8 & 53.4 & 71.7 & 18.3 \\
net house & 81.0 & 86.1 & 5.2 & 79.4 & 83.5 & 4.0 \\
other & 10.3 & 18.0 & 7.7 & 14.3 & 10.2 & -4.0 \\
real estate & 62.5 & 107.6 & 45.1 & 78.5 & 55.8 & -22.8 \\
stock & 0.0 & 97.7 & 97.7 & 76.6 & 0.0 & -76.6 \\
transp & 16.6 & 19.5 & 2.9 & 17.4 & 17.7 & 0.3 \\
total & 310.6 & 555.7 & 245.1 & 395.0 & 298.1 & -96.9
\end{tabular}


Table 4

Labor force status

\begin{tabular}{lcccccccc} 
& \multicolumn{2}{c}{1992} & \multicolumn{2}{c}{1994} & \multicolumn{2}{c}{1996} & \multicolumn{2}{c}{1998} \\
& Number & Fraction & Number & Fraction & Number & Fraction & Number & Fraction \\
Full time & 5,419 & 0.55 & 4,333 & 0.49 & 3,596 & 0.42 & 2,886 & 0.35 \\
Part time & 995 & 0.10 & 832 & 0.09 & 612 & 0.07 & 557 & 0.07 \\
Unemployed & 255 & 0.03 & 216 & 0.02 & 134 & 0.02 & 91 & 0.01 \\
Partly retired & 334 & 0.03 & 446 & 0.05 & 620 & 0.07 & 705 & 0.09 \\
Retired & 1,325 & 0.13 & 1,861 & 0.21 & 2,271 & 0.27 & 2,671 & 0.33 \\
Not in LF, not & 1,497 & 0.15 & 1,157 & 0.13 & 1,238 & 0.15 & 1,222 & 0.15 \\
retired & & & & & & & & \\
Total & 9,825 & 1.00 & 8,845 & 1.00 & 8,471 & 1.00 & 8,132 & 1.00 \\
\hline
\end{tabular}

Table 5

Transitions from full-time work, age-eligible cohorts (1931-1941)

\begin{tabular}{|l|l|l|l|l|l|l|}
\hline & \multicolumn{5}{|l|}{ Percent of workers in the following wave } \\
\hline $\begin{array}{l}\text { Full-time } \\
\text { workers }\end{array}$ & Observations & full-time & part-time & $\begin{array}{l}\text { partial } \\
\text { retirement }\end{array}$ & $\begin{array}{l}\text { not in labor } \\
\text { force }\end{array}$ & total \\
\hline 1992 & 4812 & 80.8 & 5.5 & 3.1 & 10.6 & 100.0 \\
\hline 1994 & 3944 & 77.0 & 4.6 & 5.0 & 13.5 & 100.0 \\
\hline 1996 & 3255 & 74.7 & 4.5 & 5.7 & 15.1 & 100.0 \\
\hline
\end{tabular}

Table 6

P62 as a qualitative predictor of labor force participation: mean P62 by Age and Work Status in 1998. Panel data, age-eligible cohort

\begin{tabular}{|l|l|l|l|l|l|}
\hline & \multirow{2}{*}{ Baseline wave } & \multirow{2}{*}{ Age in 1998 } & Working full-time in 1998 & \multicolumn{2}{l|}{ Not working full-time in 1998 } \\
\cline { 3 - 6 } & 62 & observations & Mean P62 & observations & Mean P62 \\
\hline Wave 1 & 63 & 190 & 63.5 & 278 & 35.0 \\
\hline & 63 & 156 & 64.6 & 281 & 40.7 \\
\hline & 64 & 125 & 70.2 & 283 & 41.2 \\
\hline Wave 2 & 62 & 175 & 63.2 & 244 & 32.8 \\
\hline & 63 & 148 & 72.5 & 234 & 36.9 \\
\hline & 64 & 117 & 76.5 & 229 & 40.7 \\
\hline Wave 3 & 62 & 167 & 71.0 & 207 & 31.1 \\
\hline & 63 & 133 & 82.0 & 154 & 40.6 \\
\hline & 64 & 47 & 88.3 & 39 & 35.8 \\
\hline
\end{tabular}


Table 7

P62 as a quantitative predictor of labor force participation. Panel data, age-eligible cohort

\begin{tabular}{|c|c|c|c|c|c|c|}
\hline \multirow[b]{2}{*}{ Baseline wave } & \multicolumn{2}{|c|}{ Age in 1994} & \multicolumn{2}{|c|}{ Age in 1996} & \multicolumn{2}{|c|}{ Age in 1998} \\
\hline & 62 & 63 & 62 & 63 & 62 & 63 \\
\hline \multicolumn{7}{|l|}{ Wave 1} \\
\hline observations & 368 & 203 & 412 & 383 & 468 & 437 \\
\hline mean SP62 & 55.6 & 59.4 & 49.5 & 49 & 46.6 & 49.2 \\
\hline percent working full-time & 51.6 & 49.8 & 41.3 & 36.8 & 40.6 & 35.7 \\
\hline \multicolumn{7}{|l|}{ Wave 2} \\
\hline observations & & & 348 & 333 & 419 & 382 \\
\hline mean SP62 & & & 51.3 & 54.3 & 45.5 & 50.7 \\
\hline percent working full-time & & & 45.4 & 40.8 & 41.8 & 38.7 \\
\hline \multicolumn{7}{|l|}{ Wave 3} \\
\hline observations & & & & & 374 & 287 \\
\hline mean SP62 & & & & & 48.9 & 59.8 \\
\hline percent working full-time & & & & & 44.7 & 46.3 \\
\hline
\end{tabular}




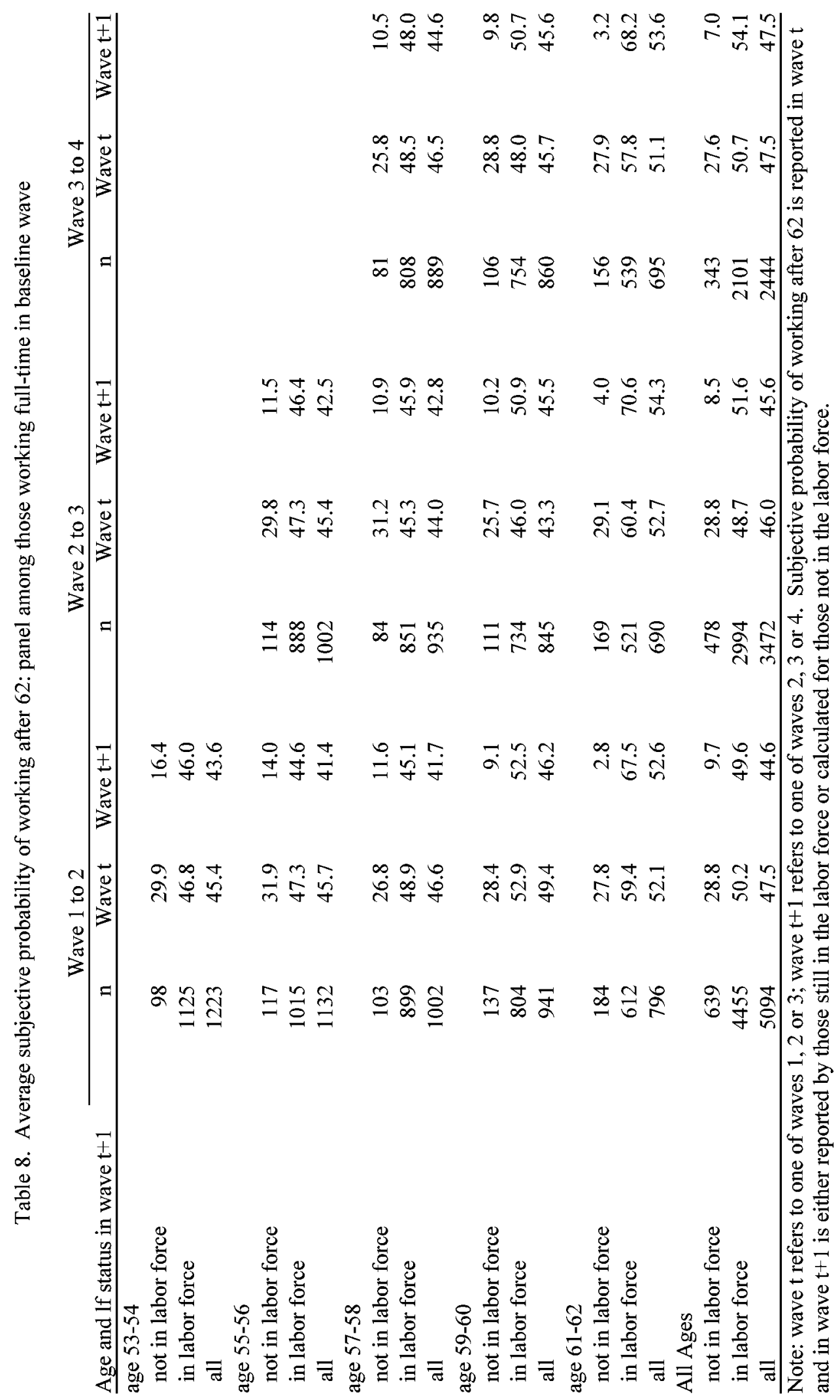




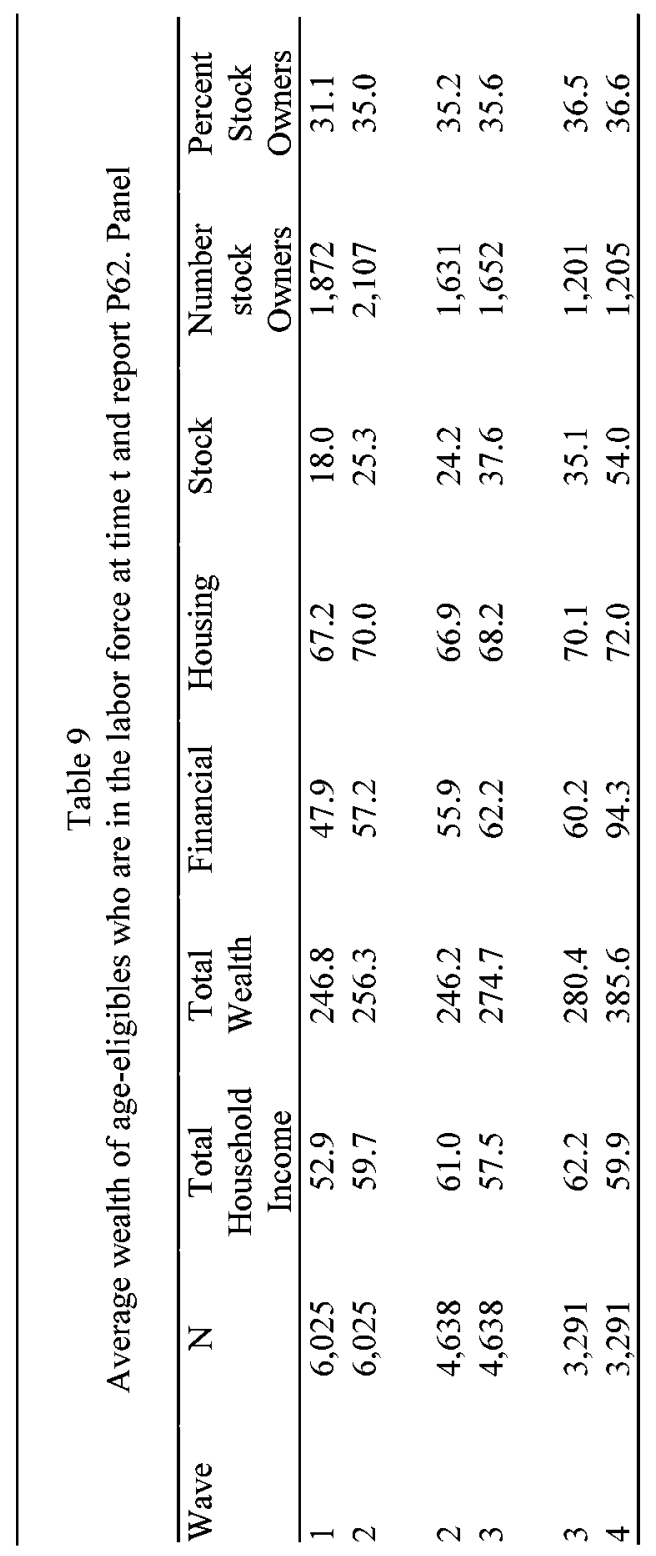




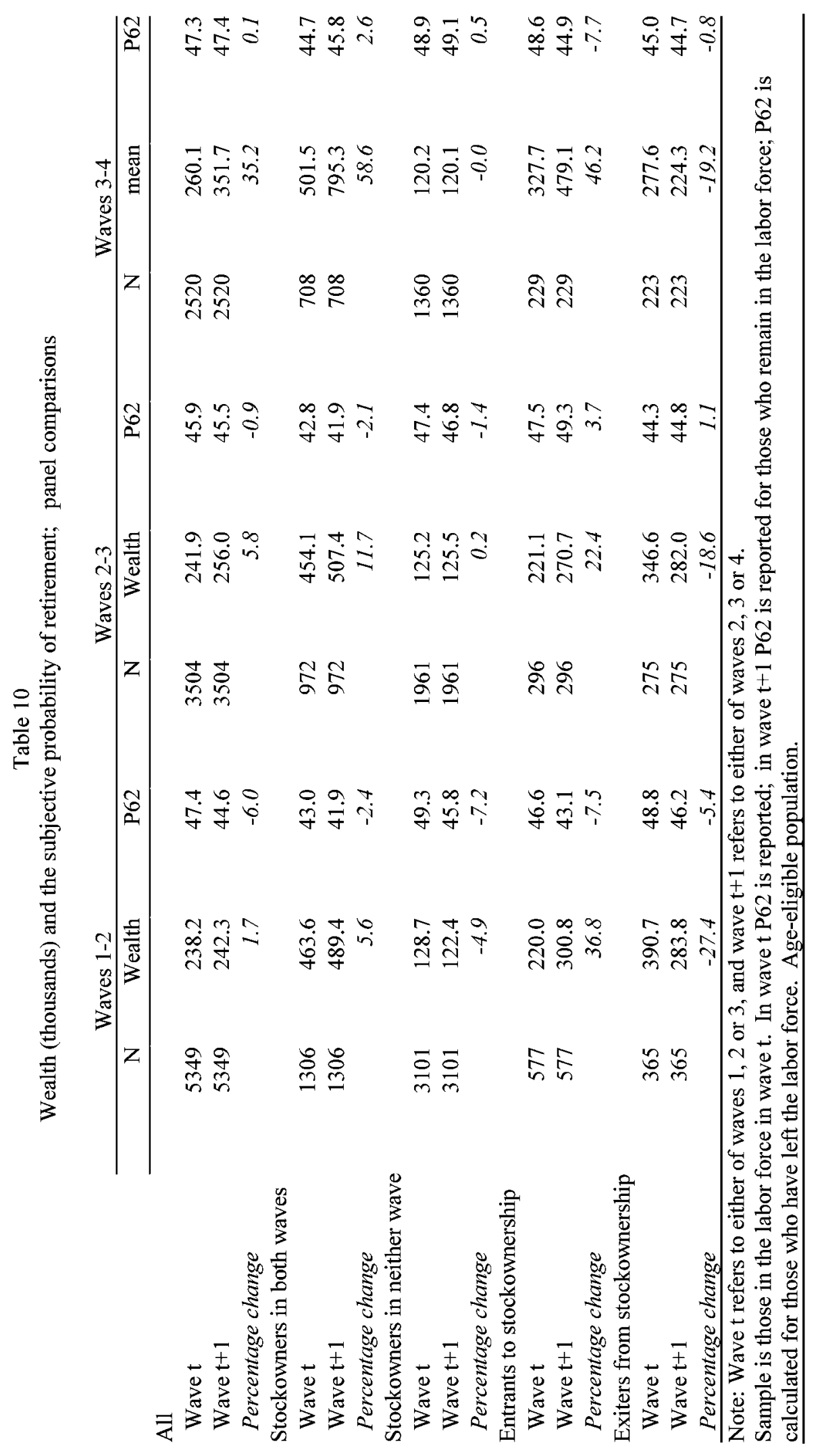




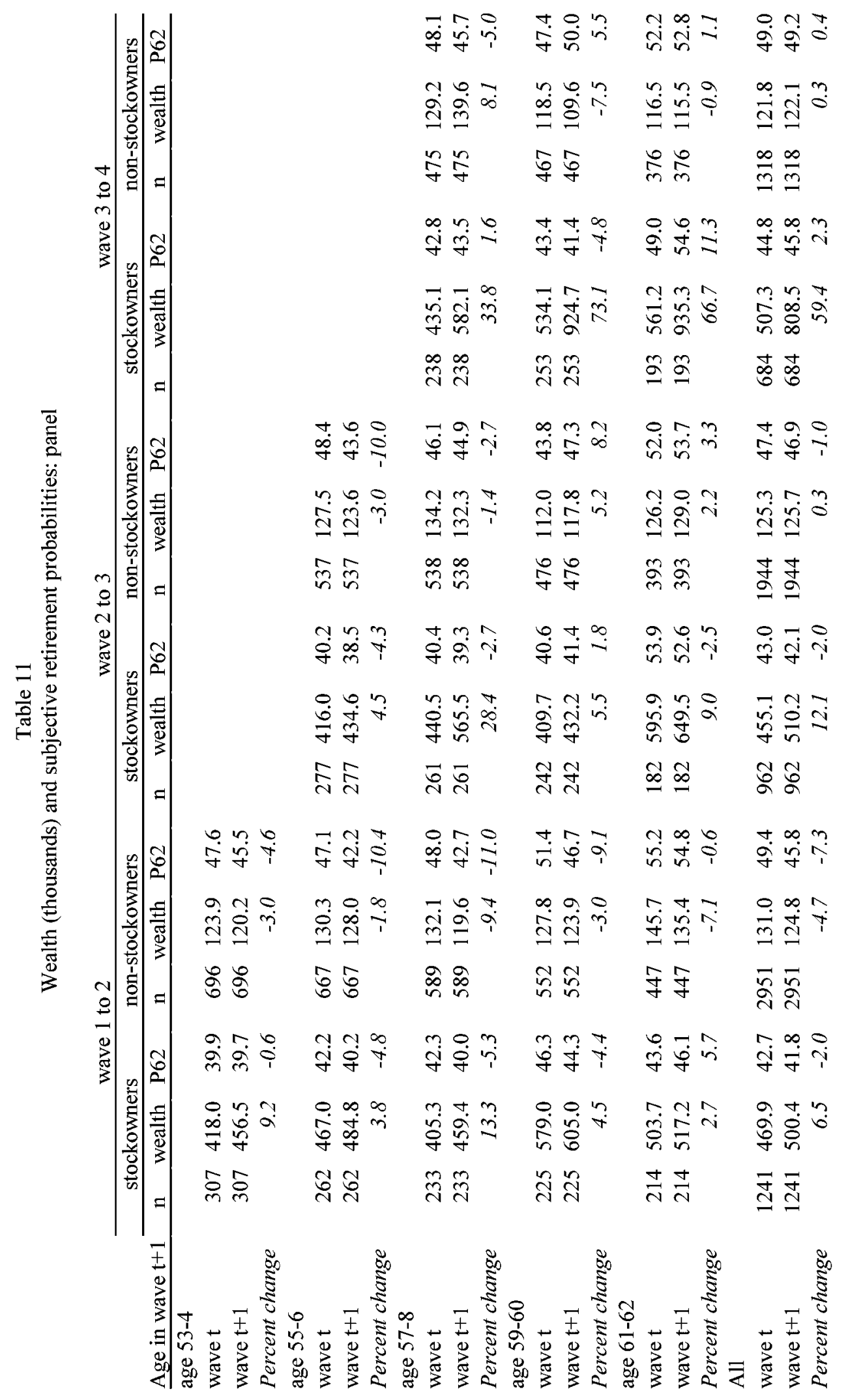


Table 12

Determinants of the change in the subjective probability of retirement, wave 3 to wave 4 (percent change)

Owned stock at wave 3

Stock owners: wave 3 wealth

\begin{tabular}{cc} 
Estimated coefficient & t-statistic \\
\hline 1.24 & 0.16 \\
-0.30 & -0.54 \\
-0.27 & -1.37 \\
1.65 & 0.96 \\
4.22 & 1.58 \\
0.47 & 0.15 \\
1.91 & 0.66 \\
-0.06 & -0.18 \\
-2.19 & -0.86 \\
0.52 & 0.84 \\
0.23 & 0.08
\end{tabular}

Non-stock owners: wave 3 wealth

DB pension: newly eligible

DB pension: previously eligible

DB pension: not yet eligible

DB pension: eligibility missing

Marital status

Health limits work

0.23

0.08

Education

Note: Estimated over 2508 workers at wave 3. Average change is approximately zero. Wealth is measured as inverse arcsine which is approximately the same as log wealth except for very small, zero or negative wealth.

Table 13

P62 and wealth (thousands) by type of pension plan

\begin{tabular}{lcccccc}
\hline & \multicolumn{2}{c}{ DB plan } & \multicolumn{2}{c}{ DC plan } & \multicolumn{2}{c}{ No plan } \\
\cline { 2 - 7 } Wave 1 & Wealth & P62 & Wealth & P62 & Wealth & P62 \\
\cline { 2 - 7 } Wave 2 & 209.7 & 42.3 & 237.5 & 50.1 & 142.6 & 47.2 \\
Percent change & 221.5 & 39.8 & 280.0 & 46.5 & 143.5 & 44.9 \\
Wave 2 & 5.7 & -5.7 & 17.9 & -7.2 & 0.6 & -4.8 \\
Wave 3 & 213.1 & 39.9 & 271.1 & 47.7 & 138.8 & 48.1 \\
Percent change & 232.2 & 40.2 & 278.9 & 47.8 & 141.8 & 47.3 \\
Wave 3 & 9.0 & 0.6 & 2.9 & 0.2 & 2.2 & -1.7 \\
Wave 4 & 227.3 & 41.5 & 306.6 & 47.8 & 151.3 & 52.0 \\
Percent change & 254.4 & 42.2 & 538.1 & 50.6 & 181.1 & 48.5 \\
\hline
\end{tabular}


Table 14

Mean assets, the subjective probability of working and expenditures

\begin{tabular}{rrrrrr}
\hline $\mathrm{N}$ & $\begin{array}{r}\text { Net asset wealth } \\
\text { (thousands) }\end{array}$ & $\begin{array}{r}\text { Probability of } \\
\text { working }\end{array}$ & $\begin{array}{r}\text { Expenditures } \\
\text { on eating out }\end{array}$ & $\begin{array}{r}\text { Expenditures } \\
\text { on food }\end{array}$ & $\begin{array}{r}\text { Total monthly } \\
\text { expenditures }\end{array}$ \\
\hline
\end{tabular}

Stockholders in both waves

\begin{tabular}{|c|c|c|c|c|c|c|}
\hline Wave 2 & 564 & 408.9 & 41.8 & 37.0 & 82.9 & \\
\hline Wave 3 & 564 & 438.0 & 40.7 & 37.8 & 83.6 & \\
\hline Percent change & & 7.1 & -2.5 & 2.1 & 0.8 & \\
\hline Wave 3 & 440 & 536.9 & 46.3 & & & 2995 \\
\hline Wave 4 & 440 & 907.8 & 45.8 & & & 2979 \\
\hline Percent change & & 69.1 & -1.2 & & & -0.5 \\
\hline \multicolumn{7}{|c|}{ Stockholders in neither wave } \\
\hline Wave 2 & 870 & 145.4 & 48.5 & 26.3 & 77.0 & \\
\hline Wave 3 & 870 & 148.0 & 48.5 & 30.4 & 80.5 & \\
\hline Percent change & & 1.8 & -0.1 & 15.7 & 4.5 & \\
\hline Wave 3 & 830 & 115.7 & 50.6 & & & 1676 \\
\hline Wave 4 & 830 & 121.1 & 49.4 & & & 1708 \\
\hline Percent change & & 4.6 & -2.2 & & & 1.9 \\
\hline \multicolumn{7}{|c|}{ Entrants into stockholding } \\
\hline Wave 2 & 172 & 245.1 & 46.2 & 31.9 & 79.3 & \\
\hline Wave 3 & 172 & 271.4 & 49.6 & 37.9 & 80.5 & \\
\hline Percent change & & 10.8 & 7.5 & 18.6 & 1.5 & \\
\hline Wave 3 & 137 & 380.7 & 46.2 & & & 2635 \\
\hline Wave 4 & 137 & 549.6 & 41.9 & & & 2487 \\
\hline Percent change & & 44.4 & -9.4 & & & -5.6 \\
\hline \multicolumn{7}{|c|}{ Exiters from stockholding } \\
\hline Wave 2 & 149 & 334.3 & 43.0 & 34.0 & 84.3 & \\
\hline Wave 3 & 149 & 311.7 & 46.0 & 35.2 & 83.3 & \\
\hline Percent change & & -6.8 & 7.1 & 3.4 & -1.2 & \\
\hline Wave 3 & 115 & 275.6 & 46.3 & & & 2082 \\
\hline Wave 4 & 115 & 255.6 & 50.1 & & & 2226 \\
\hline Percent change & & -7.3 & 8.2 & & & 6.9 \\
\hline
\end{tabular}

